\title{
Unscrambling the genomic chaos of osteosarcoma reveals extensive transcript fusion, recurrent rearrangements and frequent novel TP53 aberrations
}

\author{
Susanne Lorenz ${ }^{1,5}$, Tale Barøy ${ }^{1,14}$, Jinchang Sun ${ }^{2,5}$, Torfinn Nome ${ }^{3,10}$, Daniel Vodák ${ }^{1}$, \\ Jan-Christian Bryne ${ }^{1,2}$, Anne-Mari Håkelien ${ }^{1}$, Lynnette Fernandez-Cuesta6,7, Birte \\ Möhlendick ${ }^{8}$, Harald Rieder ${ }^{8}$, Karoly Szuhai ${ }^{9}$, Olga Zaikova ${ }^{4}$, Terje C. Ahlquist ${ }^{3,10}$, \\ Gard O. S. Thomassen ${ }^{3,10}$, Rolf I. Skotheim ${ }^{3,10}$, Ragnhild A. Lothe R, $^{3,10}$, Patrick S. \\ Tarpey $^{11}$, Peter Campbell ${ }^{11}$, Adrienne Flanagan ${ }^{12,13}$, Ola Myklebost ${ }^{1,5, *}$ and Leonardo \\ A. Meza-Zepeda ${ }^{1,2,5, *}$ \\ ${ }^{1}$ Department of Tumor Biology, Oslo University Hospital, Norwegian Radium Hospital, Oslo, Norway \\ ${ }^{2}$ Genomics Core Facility, Department of Core Facilities, Oslo University Hospital, Norwegian Radium Hospital, Oslo, Norway \\ ${ }^{3}$ Department of Molecular Oncology, Institute for Cancer research, Oslo University Hospital, Norwegian Radium Hospital, \\ Oslo, Norway \\ ${ }^{4}$ Clinic for Cancer, Surgery and Transplantation, Oslo University Hospital, Norwegian Radium Hospital, Oslo, Norway \\ ${ }^{5}$ Norwegian Cancer Genomics Consortium, Norway \\ ${ }^{6}$ Department of Translational Genomics, Center of Integrated Oncology Cologne-Bonn, University of Cologne, Cologne, \\ Germany \\ ${ }^{7}$ Genetic Cancer Susceptibility Group, International Agency for Research on Cancer (IARC-WHO), Lyon, France \\ 8 Institute for Human Genetics, University Hospital Düsseldorf, Düsseldorf, Germany \\ ${ }^{9}$ Department of Molecular Cell Biology, Leiden University Medical Center, Leiden, The Netherlands \\ ${ }^{10}$ Centre for Cancer Biomedicine, Faculty of Medicine, University of Oslo, Oslo, Norway \\ ${ }^{11}$ Wellcome Trust Sanger Institute, Hinxton, UK \\ 12 Royal National Orthopaedic Hospital, Middlesex, UK \\ ${ }^{13}$ UCL Cancer Institute, University College London, London, UK \\ ${ }^{14}$ Institute for Clinical Medicine, Faculty of Medicine, University of Oslo, Oslo, Norway \\ * These authors shared last authorship
}

Correspondence to: Leonardo A. Meza-Zepeda, email: Leonardo.Meza-Zepeda@rr-research.no

Keywords: bone cancer, osteosarcomas, gene fusion, trans-splicing, DNA repair

Received: July 16, 2015

Accepted: November 15, 2015

Published: December 11, 2015

\section{ABSTRACT}

In contrast to many other sarcoma subtypes, the chaotic karyotypes of osteosarcoma have precluded the identification of pathognomonic translocations. We here report hundreds of genomic rearrangements in osteosarcoma cell lines, showing clear characteristics of microhomology-mediated break-induced replication (MMBIR) and end-joining repair (MMEJ) mechanisms. However, at RNA level, the majority of the fused transcripts did not correspond to genomic rearrangements, suggesting the involvement of trans-splicing, which was further supported by typical transsplicing characteristics. By combining genomic and transcriptomic analysis, certain recurrent rearrangements were identified and further validated in patient biopsies, including a PMP22-ELOVL5 gene fusion, genomic structural variations affecting RB1, MTAP/CDKN2A and MDM2, and, most frequently, rearrangements involving TP53. Most cell lines $(7 / 11)$ and a large fraction of tumor samples $(10 / 25)$ showed TP53 rearrangements, in addition to somatic point mutations ( 6 patient samples, 1 cell line) and MDM2 amplifications ( 2 patient samples, 2 cell lines). The resulting inactivation of p53 was demonstrated by a deficiency of the radiation-induced DNA damage response. Thus, TP53 rearrangements are the major mechanism of p53 inactivation in osteosarcoma. Together with active MMBIR and MMEJ, this inactivation 


\begin{abstract}
probably contributes to the exceptional chromosomal instability in these tumors. Although rampant rearrangements appear to be a phenotype of osteosarcomas, we demonstrate that among the huge number of probable passenger rearrangements, specific recurrent, possibly oncogenic, events are present. For the first time the genomic chaos of osteosarcoma is characterized so thoroughly and delivered new insights in mechanisms involved in osteosarcoma development and may contribute to new diagnostic and therapeutic strategies.
\end{abstract}

\section{INTRODUCTION}

The chaotic chromosomes and heterogeneity of osteosarcomas has made the identification of pathognomonic mutations difficult. Spectral karyotyping has revealed a large number of structural and chromosomal aberrations, with translocations generating complex derivative chromosomes apparently harboring large numbers of fusion sequences [1]. The complexity is exacerbated by exceptionally high frequency of copy number changes [2]. Due to the hyperdiploid constitution of many different derivatives, with hidden translocations, amplified segments and deletions, as well as double minute chromosomes, most cell divisions would be expected to give daughter cells with different karyotypes, resulting in high intratumor heterogeneity. In spite of this, core components of the scrambled genome will be selected for and may be identified by being present in the majority of cells, because over time many of the variant genomes will be lost from the population. Although cell lines have over many years been selected for in vitro growth properties, they are important workhorses of preclinical research, and maintain many of the central oncogenic mechanisms [3]. Observations initially identified in cell lines may subsequently be validated in patient samples, as has been done here. A clear advantage of the availability of cell line data is that in vitro models for functional analysis are immediately available.

An increasing number of pathognomonic translocations have been identified in sarcoma subtypes, but not yet in osteosarcomas. On the other hand, focused copy number changes could be identified, among them, frequent deletion of $\operatorname{LSAMP}[4,5]$, and amplification of $C D K 4$ and MDM2 [6], leading to inactivation of $R B 1$ [7] and TP53 [8], respectively. Especially the RB1 and p53 pathways appear to be important for osteosarcoma development, as survivors from retinoblastoma have a high risk of secondary osteosarcomas [9], and sarcomas are prevalent in Li-Fraumeni families with germ line mutations of TP53 [10]. However, it was for a long time an enigma why mutations in TP53 had only been observed in about 15-20\% of sporadic osteosarcomas [11, 12], although p53 is inactivated in an additional 10-20\% by amplification and overexpression of MDM2 [13-15]. Some complementary mechanisms have been proposed [16], but only recently next generation sequencing (NGS) analysis revealed frequent aberrations of TP53 in osteosarcoma by genomic rearrangements that would be missed by traditional mutation analysis $[17,18]$. Also focused but random kataegis was observed, but not affecting the TP53 region [19]. However, in these study only clinical samples were interrogated, and no functional studies on the effect of TP53 rearrangements could be done.

\section{RESULTS}

\section{RNA sequencing and identification of fusion transcripts in cell lines}

Fusion transcripts were identified by sequencing the transcriptomes of 11 osteosarcoma cell lines (see Supplementary Table S1 for an overview over all samples used). On average, 40 million paired-end reads per sample were generated. A total of 502 candidate fusion transcripts were detected after filtering, varying from a few candidates to more than a hundred fusions per sample (Supplementary Table S2).

Seventeen candidate fusions found in multiple samples and/or showing intact exon structure were chosen for validation in 3 cell lines using normal bone and osteoblasts as controls. Of these candidate fusions, 15 gave the predicted product sizes using breakpointspanning PCR, and Sanger sequencing confirmed the identities of 13 of these, giving a validation rate of 76 $\%$ (Table 1). However, certain fusion transcripts were detected by PCR in additional samples that were negative by RNA-Seq, suggesting expression levels that were too low to be detected at the sequence depth used. The EIF5A-HMGN2 and EEF1A1-VIM fusion transcripts were detected and validated in all tested cell lines and both controls, indicating that these fusions were not cancerspecific.

The expression levels of the wild-type transcripts involved in fusions were significantly enriched for moderate to high expression (Wilcoxon rank-sum test, p-values $<6.36 \mathrm{e}-05$ ), suggesting a fusion mechanism associated with high expression. In contrast, the majority of fusion transcripts were expressed at lower level.

All sequencing data are available at the European Nucleotide Archive (ENA) under accession number PRJEB7574 (http://www.ebi.ac.uk/ena/data/view/ PRJEB7574). 
Table1: Validation results for 17 candidate fusion transcripts in the osteosarcoma cell lines

\begin{tabular}{|c|c|c|c|c|c|c|c|}
\hline \multirow{2}{*}{ Fusion transcript } & \multirow{2}{*}{ Positive by RNA-Seq } & \multicolumn{5}{|c|}{ Breakpoint PCR validation } & \multirow{2}{*}{$\begin{array}{c}\text { Sanger } \\
\text { sequencing }\end{array}$} \\
\hline & & IOR/OS15 & IOR/MOS & MHM & normal bone & osteoblast & \\
\hline$C O L 1 A 2-M M P 14$ & IOR/OS15, IOR/OS18 & + & + & + & - & - & + \\
\hline FUS-LGMN & IOR/OS15, MG-63 & + & + & - & - & - & + \\
\hline$D H F R-P A B P C 1$ & IOR/OS15 & + & + & - & - & - & + \\
\hline PTMA-NPM1 & IOR/OS15 & + & + & + & - & - & + \\
\hline PMP22-ELOVL5 & IOR/OS15 & + & + & - & - & - & + \\
\hline CDC5L-BTBD9 & IOR/OS15 & + & - & - & - & - & + \\
\hline RAl1-CLIC5 & IOR/OS15 & + & - & - & - & - & + \\
\hline TP53-PPRAD & IOR/OS15 & + & - & - & - & - & + \\
\hline MRPL39-MAML3 & IOR/OS15 & + & - & - & - & - & + \\
\hline PLXNA2-RUNX1 & IOR/OS15 & + & - & - & - & - & + \\
\hline EIF5A-HMGN2 & $\begin{array}{c}\text { IOR/OS15, MG-63, } \\
\text { Saos-2 }\end{array}$ & + & + & + & + & + & + \\
\hline EEF1A1-VIM & $\begin{array}{c}\text { IOR/OS15, IOR/OS18, } \\
\text { IOR/SARG }\end{array}$ & + & + & + & + & + & + \\
\hline EIF2S1-RBM25 & IOR/OS15 & + & - & - & - & - & + \\
\hline COL1A1-HSP9OAB1 & IOR/OS15, MG-63 & + & - & + & - & - & - \\
\hline SCO1-CLIC5 & IOR/OS15 & + & + & + & + & + & - \\
\hline CREB3L1-HNRPA & IOR/OS15 & - & - & - & - & - & ND \\
\hline PDZRN4-PKM2 & $\begin{array}{c}\text { IOR/OS15, IOR/OS18, } \\
\text { MHM }\end{array}$ & - & - & - & - & - & ND \\
\hline
\end{tabular}

(“+" positively validated, "-" negatively validated, "ND" not determinable)

\section{Identification of structural variations by whole genome sequencing (WGS)}

All cell lines showed multiple complex chromosomal rearrangements as visualized by spectral karyotyping (SKY, Fig. 1a). Although the resolution is very low, it demonstrated the presence of large numbers of translocations.

The genomes of four cell lines, IOR/OS15, IOR/ OS18, MG-63 and ZK-58, were fully sequenced. Approximately $95 \%$ of the more than 1.2 billion pairedend reads from each sample could be mapped to the genome, giving a median coverage of approximately $30 x$. Upon further filtering, analysis by DELLY showed a high number of deletions, tandem duplications, inversions and interchromosomal translocations (Fig. 2). In general, the frequencies of the different types of rearrangements were similar in the four cell lines, except for a very low number of tandem duplications in IOR/OS15. Large heterogeneity was revealed by allele frequencies of interchromosomal rearrangements from 1 to $50 \%$. The genomic translocations identified in each sample are given in Supplementary Table S3 and translocations with a frequency above $10 \%$ are presented in Figure 1b. No translocations were common to all four cell lines, but in all cases TP53 was affected by rearrangements involving various fusion partners.

All rearrangements were further investigated for microhomology at the breakpoints. We did not detect similarities of more than $25 \mathrm{bp}$ on both sides of the breakpoints, and the rearrangement types were grouped into three categories: 6-25 bp, 1-5 bp, or without microhomology. The ratios of these three categories were similar among translocations, inversions and tandem duplications in all samples, showing that the majority (80-93\%) of breakpoints harbored no more than $5 \mathrm{bp}$ of microhomology. In contrast, deletions were almost 10 times more frequent, and greater than $55 \%$ of these breakpoints harbored microhomologies of 6-25 bp. Interestingly, there was an inverse correlation between the length of deletions and the length of sequence homology at the breakpoint (Fig. 2). The frequency of longer homologies was reduced for deletions longer than $5 \mathrm{~kb}$ and showed microhomology patterns more similar to the patterns of translocations, inversions and tandem 
duplications. The same pattern was observed for deletions longer than $10 \mathrm{~kb}$, which had even more pronounced similarity to microhomology patterns of the other types of genomic rearrangements. The identified microhomology pattern for all rearrangement types differed significantly (p-values $<1.00 \mathrm{e}-05$ ) from patterns identified by analyzing a random set of 500 sequences derived from the human genome, demonstrating a specific enrichment of 1-5 bp and 6-25 bp microhomologies at the breakpoints.

These findings suggest that somewhat different microhomology mediated DNA repair mechanisms, as i.e. non-homologous end-joining (NHEJ) and microhomology-mediated end-joining (MMEJ) repair, are involved in the generation of the genomic rearrangements and deletions shorter than $5 \mathrm{~kb}$.

Analysis of the genomic distribution of the structural variations showed dense clusters of rearrangements, a characteristic of chromothripsis, in all four cell lines (Fig. 1c). Detailed analysis of the distance between the breakpoints by testing the goodness-of-fit using the null model of random breakpoints following an exponential distribution with the mean of all observed distances [20] was significant ( $p$-values $<0.005)$ and confirmed the observed feature of chromothripsis. This model was further supported by the randomness of the orientation of DNA fragment joins. The randomness of our data was proven by a Chi-square test for the given probability (p-values $>0.9)$. However, while chromothripsis is expected to be associated with loss or a neutral copy number [21, 22], we observed more than 6-fold increased coverage compared to the median in these regions. The extreme copy number changes of these cell lines have previously been described using SNP-CGH [3].
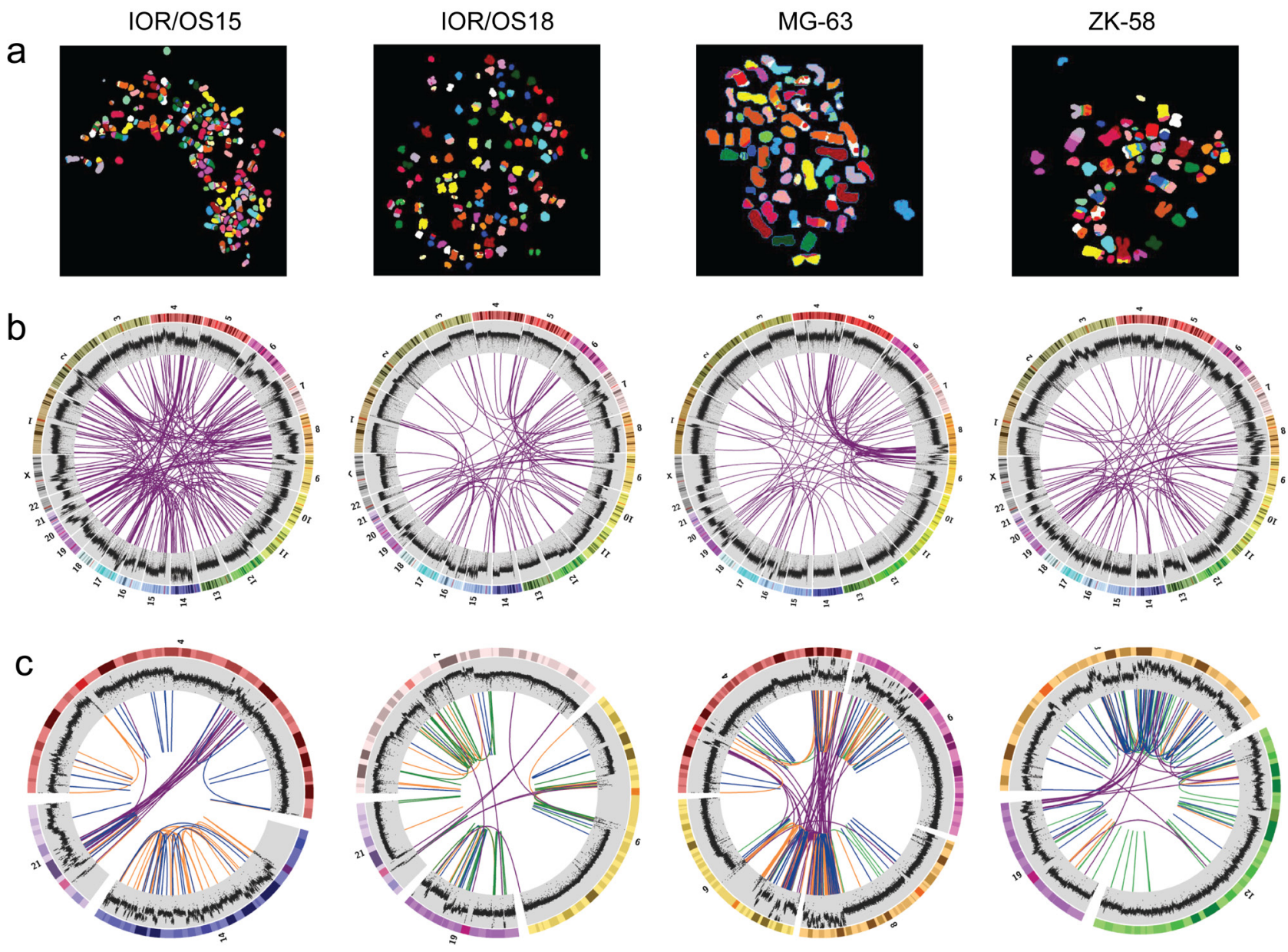

Figure 1: Visualization of the genomic chaos in osteosarcoma. a. Example single cell multicolor spectral karyotypes for each cell line demonstrating the genomic complexity and high numbers of translocations. b. Circos plots showing genome-wide interchromosomal translocations (purple lines) identified by WGS with allele frequencies of $\geq 10 \%$. The outermost circles illustrate the chromosome idiograms followed by the plot of the genome coverage (binary logarithmic scale ranging from $2\left(\log _{2} 4\right)$ to 8 ( $\left.\log _{2} 256\right)$, increasing from center towards periphery, $50 \mathrm{~K}$ window size). Changes in coverage indicate copy number variations with increase indicating gain and decrease indicating loss. c. Circos plots of rearrangement clusters showing chromothripsis-like characteristics of breakpoint distribution within certain chromosomes. Purple lines indicate translocations, orange lines inversions, green lines duplications and blue lines deletions. The coverage plot illustrates high local increase of the copy number, which does not support the copy number neutral chromothripsis model. 


\section{Comparison of RNA-Seq and WGS}

For four of the cell lines (IOR/OS15, IOR/OS18, MG-63 and ZK-58) both the whole genome and the transcriptome were sequenced. Surprisingly, for the 182 different fusion transcripts identified in these four cell lines, corresponding genome fusions could only be found for 19. Reduced detection stringency did not improve this rate. Eleven of 93 fusion transcripts showed underlying genomic rearrangements in IOR/OS15, 6 of 101 transcripts in MG-63, 2 of 115 in ZK-58 and none of the 160 fusion transcripts in IOR/OS18 (Table 2). Among the 19 expressed fusion genes, TP53 was observed three times (IOR/OS15, 2xMG-63). Eight of the 19 fusion transcripts were caused by intrachromosomal rearrangements (deletions or inversions) (translocations). The remaining rearrangements were interchromosomal. Six of the 13 fusion transcripts confirmed by breakpoint PCR at the RNA level (Table 1) could not be confirmed at the genomic level. Even manual inspection of the raw data did not reveal any evidence of underlying genomic rearrangements. Among them were EIF5A-HMGN2 and EEF1A1-VIM, which were also observed in normal samples. One of the fusion transcripts, SCO1-CLIC5, for which we were unable to design sufficiently good primers to confirm by breakpoint-spanning PCR, was however unequivocally confirmed by the full genome sequence, with genomic breakpoints that fit perfectly with the identified fusion transcript.

Correlating the genomic localization of
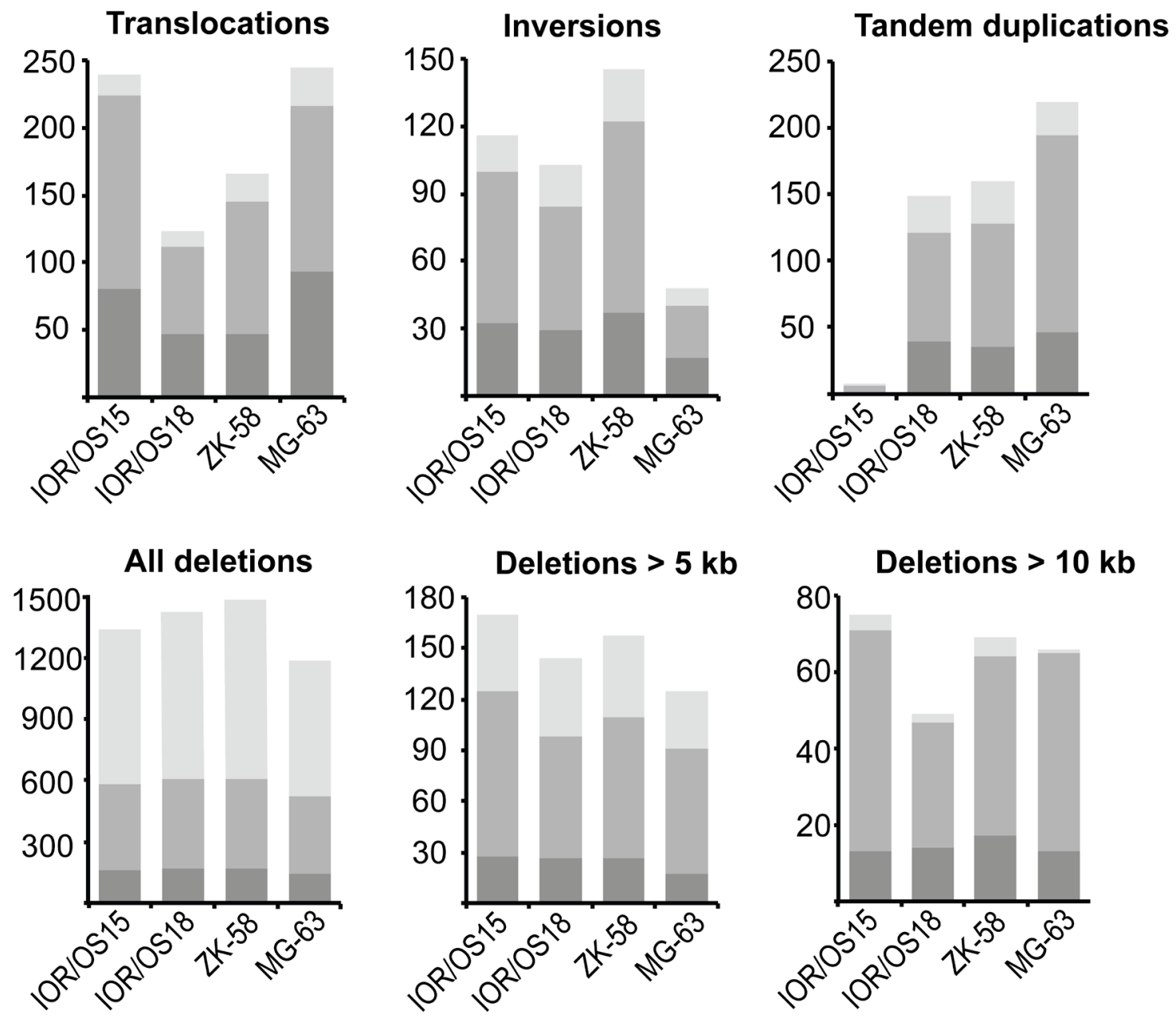

\section{6-25 bp microhomology}

1-5 bp microhomology

Without overlap

Figure 2: Abundance of the different genomic rearrangement types and their microhomology pattern. The rearrangements are grouped by type (translocations, inversions, tandem duplications, deletions) and divided in three categories of overlapping microhomology at the breakpoints: 6-25 bp overlap, 1-5 bp overlap and without overlap. Deletions are further divided by length, showing that smaller deletions $(<5 \mathrm{~kb})$ have a different microhomology pattern with a higher frequency of 6-25 bp long overlapping microhomology. This frequency was clearly reduced for deletions longer than $5 \mathrm{~kb}$ and more similar to the other types of rearrangements. The same tendency was found for deletions longer than $10 \mathrm{~kb}$, which showed even more similarity to the microhomology pattern of translocations, inversions and tandem duplications. 
interchromosomal rearrangements relative to genes and their expression gave similar distributions in all four cell lines. Approximately $40 \%$ of the human genome represents intragenic regions (genomic coordinates between start and end of all genes annotated in Homo sapiens GRCh37.74.gft). As 43-61\% of the breakpoints for the different cell lines fall into these regions, there apparently was no significant enrichment. Of the intragenic breakpoints, $15-22 \%$ were located in genes that were not expressed, 22-37\% showed overlap with one expressed gene, and for only 3-10\% both sides of the breakpoints were located in expressed genes (Supplementary Fig. S1). Only $0-2 \%$ resulted in a fusion transcript. Overall, the huge number of chromosomal rearrangements caused only very few fusion transcripts and accordingly the majority of fusion transcripts seem to be generated by other mechanisms.

\section{PMP22-ELOVL5 fusion}

Fusion genes confirmed at both the RNA and DNA levels were further investigated by fusion-specific TaqMan expression assays in an osteosarcoma panel containing 21 cell lines (including the 11 cell lines used for RNA-seq), 19 patient-derived xenografts and 9 clinical samples. One fusion transcript, PMP22-ELOVL5, was recurrent, detected in four cell lines (IOR/OS15, IOR/ MOS, MHM, U-2 OS), one xenograft (OKTx), and two patient samples (OS29 and OS83). As the breakpoints for this fusion are located in long introns (intron 4 of $P M P 22$, length: $8.4 \mathrm{~kb}$; intron 1 of ELOVL5, length: $53 \mathrm{~kb}$ ), the detailed genomic position could only be determined for IOR/OS15, for which WGS data was available. The expression level of the PMP22-ELOVL5 fusion transcript was highest in IOR/OS15, while more modestly expressed in the additional samples. Using 5'- and 3'- RACE, we confirmed both transcript ends of the PMP22- ELOVL5 fusion. The products had the expected sizes and the breakpoint was confirmed by Sanger sequencing. The transcript starts at the alternative start site of PMP22 at exon $1 \mathrm{~b}$ and continues until exon 4 , which is fused to exon 2 of ELOVL5 and includes the remaining exons (Fig. 3a). The final exon of PMP22 is lost in the fusion, as well as the non-coding first exon of ELOVL5. The resulting protein sequence contains the first 106 of 160 amino acids of PMP22, an additional amino acid (Phe) generated at the fusion, and the complete in frame protein sequence of ELOVL5. The rearrangement was further investigated using fluorescent in situ hybridization (FISH) of bacterial artificial chromosomes (BACs) covering the two partner genes on a tissue array of 20 osteosarcoma cell lines (including the ones analyzed by NGS). Abundant co-localization of signals was observed in IOR/OS15, validating the fusion (Fig. 3b). Additional cell lines that were positive for qPCR showed co-localization of the signals in only a fraction of the cells.
Osteosarcomas are thought to originate from a mesenchymal stem cell similar to the ones found in bone marrow [23]. When an immortalized cell line of this type (iMSC\#3 [24, 25]) was induced to osteogenic differentiation (Fig. 3c), PMP22 expression increased to a level higher than was observed in any of the osteosarcoma lines, suggesting a role in osteoblast differentiation (Supplementary Table S4). The cell line IOR/OS15, harboring the PMP22-ELOVL5 gene fusion and a genomic amplification of the whole PMP22 locus, was higher expressed only for the part of the transcript involved in the fusion (Fig. 3c). Despite the amplification, the expression level of exon 5, specific to wild-type PMP22 (lost in the gene fusion), was lower, and similar to that in the differentiated iMSC\#3. The same tendency was observed for ELOVL5: there was little change when iMSC\#3 cells were differentiated, and only IOR/OS15 exhibited higher expression (Fig. 3d, Supplementary Table S4).

The presence of the fusion gene was further investigated in 25 WGS data sets of osteosarcoma tumors (part of the International Cancer Genome Consortium, Bone cancer project). PMP22 was translocated in one of these samples, but the breakpoint in intron 3 was fused to an intergenic region of chromosome 5. Thus, this translocation $\mathrm{t}(17 ; 5)(\mathrm{p} 12 ; \mathrm{p} 15.1)$ appears to result in a truncation of the $P M P 22$ transcript rather than a bona fide fusion transcript. Because of a lack of RNA material for these samples, the presence of the fusion RNA could not be investigated.

Summarizing the findings in the two sample sets (49 samples investigated at RNA and 25 samples at DNA level), PMP22-ELOVL5 occurred at a frequency of $9 \%$ (7 of 74) and is the first recurrent fusion transcript reported in osteosarcoma.

\section{Aberrations and activity of TP53}

Another prominent finding was the frequent rearrangements of TP53. Four of eleven sequenced cell lines (KPD, MG-63, Saos-2, IOR/OS15) expressed fusion transcripts involving TP53. In MG-63, KPD and Saos-2, the fusion transcripts contained only the first (non-coding) exon, which was fused to the second exon of $V A V 1$, the sixth exon of the $D D X 39 B$ and the first exon of $S A T 2$, respectively. The translocation in MG-63 seemed to result in two different fusion transcripts, one involving the gene at the breakpoint (VAV1) and another transcript involving the gene next to it (EMR1). No further rearrangement could be found that could explain the TP53-EMR1 fusion transcript, suggesting some kind of read-through followed by splicing out of the VAV1 sequences. The transcript found in IOR/OS15 contained exons 1 to 8 (amino acids 1-306) of TP53 fused to the second exon of PPRAD. The loss of the last 87 amino acids (aa) from the IOR/OS15 fusion removes most of the nuclear localization signal and C-terminus of p53. In Saos-2, the fusion transcript is 
Table 2: Genome rearrangements resulting in fusion transcripts identified in three cell lines

\begin{tabular}{lll}
\hline Sample & Gene fusion & Rearrangement type \\
\hline IOR/OS15 & PMP22-ELOVL5 & Translocation \\
IOR/OS15 & GCC2-CCDC73 & Translocation \\
IOR/OS15 & RA11-CLIC5 & Translocation \\
IOR/OS15 & TP53-PPRAD & Translocation \\
IOR/OS15 & MRPL39-MAML3 & Translocation and deletion \\
IOR/OS15 & PLXNA2-RUNX1 & Translocation \\
IOR/OS15 & SCO1-CLIC5 & Translocation \\
IOR/OS15 & EIF2S1-RBM25 & Deletion \\
IOR/OS15 & BAZ1A-NUMB & Deletion \\
IOR/OS15 & CDC5L-BTBD9 & Inversion \\
IOR/OS15 & MRPL39-NRIP1 & Inversion \\
MG-63 & DNER-ELL2 & Translocation \\
MG-63 & CLIP4-EPHB4 & Translocation \\
MG-63 & TP53-VAV1* & Translocation \\
MG-63 & TP53-EMR1* & Translocation \\
MG-63 & MROH1-PARP10 & Inversion \\
MG-63 & BNC2-MTAP & Inversion \\
ZK-58 & CREBBP-TFAP4 & Deletion \\
ZK-58 & GDPD5-MAP6 & Deletion \\
\hline
\end{tabular}

* One genomic translocation (TP53-VAV1) causing two different fusion transcripts involving the gene at the breakpoint (VAV1) and the gene next to it (EMR1).
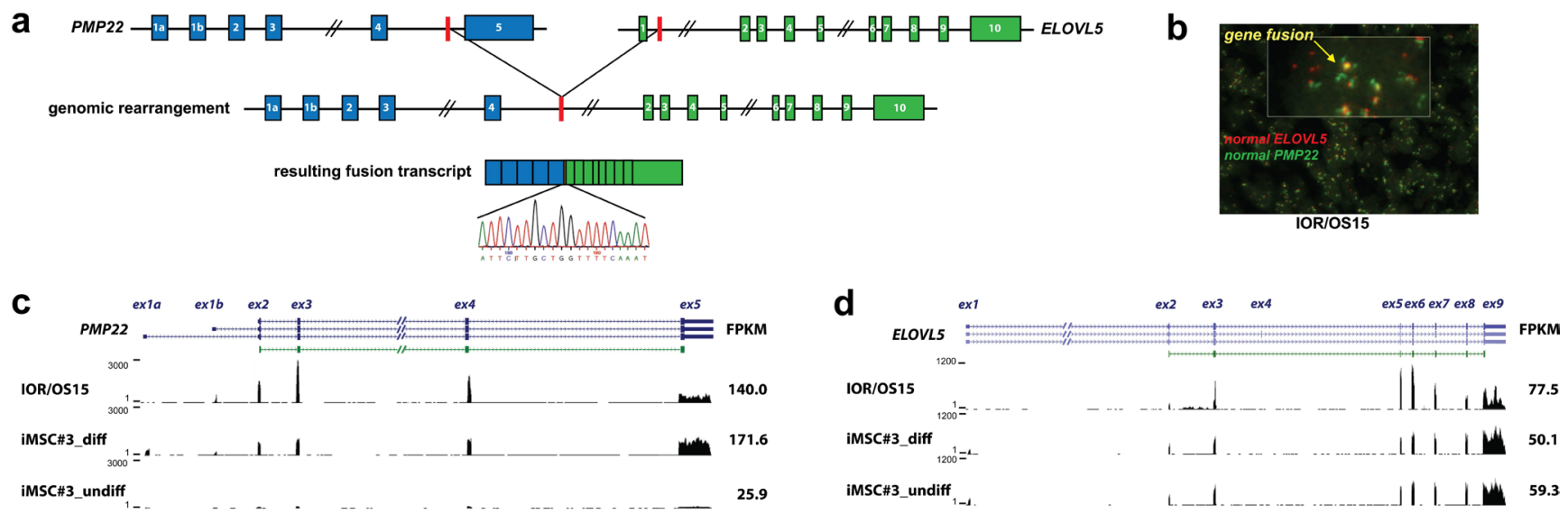

Figure 3: PMP22-ELOVL5 gene fusion. a. Schematic overview of the location of the genomic breakpoint and the resulting fusion transcript identified in the cell line IOR/OS15. Validation of the fusion transcript by Sanger sequencing confirmed the breakpoint as illustrated in the sequence chromatogram. b. Double-fusion FISH picture of IOR/OS15 in tissue microarray (cell pellets). Green and red probes identify PMP22 and ELOVL5, respectively. Colocalized signals are visible in yellow and confirm the gene fusion at the genome level. Further, normalized expression patterns of PMP22 c. and ELOVL5 d. are shown for IOR/OS15, differentiated and undifferentiated iMSC\#3 with the corresponding FPKM (Fragments Per Kilobase of exon per Million fragments mapped) calculated using Cufflinks. For IOR/OS15 a reduced expression of PMP22 exon 5 and ELOVL5 exon 1 is visible, caused by the loss of these exons in the fusion transcript. 
Table 3: Overview of TP53 aberrations and MDM2 amplification identified in the 25 osteosarcoma tumors

\begin{tabular}{|c|c|c|c|c|c|}
\hline $\begin{array}{l}\text { Gene/ } \\
\text { Sample }\end{array}$ & Type of aberration & Position & Consequence & $\begin{array}{l}\text { Aberr. allele } \\
\text { frequency }\end{array}$ & $\begin{array}{l}\text { WT allele } \\
\text { frequency }\end{array}$ \\
\hline \multicolumn{6}{|l|}{ TP53 } \\
\hline \multirow[t]{2}{*}{ PD7507a } & $\operatorname{Del}(7.5 \mathrm{Mb})$ & Intron 9 & TSS-exon i9 deleted & $40 \%$ & $20 \%$ \\
\hline & Trans & Intron 9 & Loss of exon i9-3'UTR & $40 \%$ & \\
\hline \multirow[t]{2}{*}{ PD7513a } & Trans & Intron 1 & Loss of exon2-3'UTR & $40 \%$ & $25 \%$ \\
\hline & Trans & Intron 1 & Loss of TSS and exon1 & $35 \%$ & \\
\hline \multirow[t]{2}{*}{ PD7194a } & Inv (50.3 Mb) & Intron 1 & Loss of exon2-3'UTR & $40 \%$ & $30 \%$ \\
\hline & Trans & $\begin{array}{c}1.8 \mathrm{Mb} \text { upstream } \\
\text { TP53 TSS }\end{array}$ & $\begin{array}{c}\text { Gene loss (unbalanced } \\
\text { translocation) }\end{array}$ & $30 \%$ & \\
\hline PD7197a & Small del (10 bp) & Exon5/intron5 & Splice site disruption & $55 \%$ & $45 \%$ \\
\hline PD13491a & $\begin{array}{c}\text { Del } \\
(416 \mathrm{~kb})\end{array}$ & $\begin{array}{l}364 \mathrm{~kb} \text { upstream - } 31 \mathrm{~kb} \\
\text { downstream TP53 3' UTR }\end{array}$ & Gene loss & $70 \%$ & $30 \%$ \\
\hline \multirow[t]{2}{*}{ PD13492a } & Trans & Intron 1 & Loss of exon2-3'UTR & $55 \%$ & $15 \%$ \\
\hline & Trans & Intron 1 & Loss of TSS and exon1 & $30 \%$ & \\
\hline PD13493a & $\begin{array}{c}\text { Del } \\
(72 \mathrm{~kb})\end{array}$ & $\begin{array}{c}50 \mathrm{~kb} \text { upstream - } 3 \mathrm{~kb} \\
\text { downstream TP53 }\end{array}$ & Gene loss & $60 \%$ & $40 \%$ \\
\hline \multirow[t]{2}{*}{ PD13496a } & Trans & $76 \mathrm{~kb}$ downstream TP53 & Gene loss & $50 \%$ & $30 \%$ \\
\hline & Trans & $2 \mathrm{~kb}$ upstream TP53 & Gene loss & $20 \%$ & \\
\hline \multirow[t]{2}{*}{ PD7193 } & Del (93 kb) & Intron 1 & Loss of exon2-3'UTR & $40 \%$ & $30 \%$ \\
\hline & Trans & Intron 1 & Loss of exon2-3'UTR & $30 \%$ & \\
\hline PD13485a & Del (9 kb) & Intron 9 & Loss of exon i9-3'UTR & $20 \%$ & $80 \%$ \\
\hline PD13486a & Trans & Intron 1 & Loss of exon2-3'UTR & $75 \%$ & $25 \%$ \\
\hline PD13484a & SNV & c. $843 \mathrm{C}>\mathrm{A}$ & p.D281E & $32 \%$ & $68 \%$ \\
\hline PD13487a & SNV & c. $713 \mathrm{G}>\mathrm{T}$ & p.C238F & $82 \%$ & $18 \%$ \\
\hline PD13488a & SNV & c. $764 \mathrm{~T}>\mathrm{C}$ & p. $1255 \mathrm{~T}$ & $62 \%$ & $38 \%$ \\
\hline PD7196a & SNV & c. $818 \mathrm{G}>\mathrm{T}$ & p.R273L & $47 \%$ & $53 \%$ \\
\hline PD13490a & SNV & c. $824 \mathrm{G}>\mathrm{A}$ & p.C275Y & $72 \%$ & $28 \%$ \\
\hline \multicolumn{6}{|l|}{ MDM2 } \\
\hline PD7508a & High level Ampl & chr12 q15 & Total CN of 20 & - & $\begin{array}{c}10 \text { fold } \\
\text { increased }\end{array}$ \\
\hline PD7510a & High level Ampl & chr12 q15 & Total $\mathrm{CN}$ of 60 & - & $\begin{array}{c}30 \text { fold } \\
\text { increased }\end{array}$ \\
\hline
\end{tabular}

(WT= wild-type, Aberr= aberrant, $\mathrm{Ampl}=$ amplification, Del= deletion, Trans= translocation, Inv= inversion, $\mathrm{SNV}=$ single nucleotide variation, $\mathrm{CN}=$ copy number)

the result of a long deletion after exon 1. Further analysis of the TP53 loci in the cell lines at the DNA and RNA level revealed aberrations in 5 additional cell lines. IOR/OS10 contained a truncated transcript that ended after exon 9 (aa 331) and thereby had lost the complete $\mathrm{C}$-terminal region, including the oligomerization domain and the basic region. ZK-58 and IOR/OS18 exhibited genomic translocations $(\mathrm{t}(5 ; 17)(\mathrm{q} 13.2 ; \mathrm{p} 13.1)$ and $\mathrm{t}(14 ; 17)$ (q32.2;p13.1), respectively) that generated truncated TP53 mRNAs confirmed at the RNA level. The resulting transcript for ZK-58 included only the first exon and for
IOR/OS18, exon 5-11 (aa 126-393), which led to the loss of both transactivation domains (TAD1 and TAD2) and the first 25 aa of the DNA-binding domain. In IOR/SARG, we identified a homozygous stop mutation at aa 205, resulting in the loss of the last 87 aa of the DNA-binding domain, the nuclear localization signal and the $\mathrm{C}$-terminus. The previously described deletion at bp 249-572 in IOR/ MOS [26], which resulted in a deletion affecting TAD2 and the DNA binding domain, was confirmed. Thus, 9 of 11 osteosarcoma cell lines showed fused or truncated TP53 mRNAs that compromised the p53 protein structure 
(Fig. 4a,b), with a rearrangement hot spot in intron 1 (4 samples). Wild-type TP53 mRNA was detected only in IOR/MOS, MHM and OSA. In the latter two cell lines, the pathway is inactivated by $M D M 2$ amplification, leading to 10-fold increased expression of MDM2 [26, 27]. IOR/MOS has low-level expression of TP53 from an apparently normal allele, and we do not know whether this causes haploinsufficiency or if another component of the pathway also is affected.

To determine the activity of the p53 pathway, all cell lines were subjected to radiation-induced DNA damage, and the induction of two major targets downstream of p53 was determined $-C D K N 1 A$ (p21) and $B A X$. The cell line U-2 OS, which is a human osteosarcoma cell line expressing wild-type p53 and RB1, but lacking p16 [28, 29], was used as the control. The comparison of expression levels before and 8 hours after radiation-induced DNA damage showed induction of $C D K N 1 A$ and $B A X$ in the control U-2 OS but no significant increase in any of the other tested cell lines (Fig. 4d). A slight increase was detected in MHM and OSA, the two cell lines harboring wild type p53 but also MDM2 amplification. This demonstrates loss-of function of p53 in all osteosarcoma cell lines (except U-2 OS), caused in 7 cases by genomic rearrangements affecting TP53, in 2 cases by $M D M 2$ amplification and in 1 case by a mutation and a small deletion (Fig. 4c).

Detailed investigation of the TP53 locus in the WGS data from 25 osteosarcoma tumors revealed rearrangements that directly affected TP53 in ten samples (Table 3), also with a hotspot in intron 1 (5 samples) and a second hotspot in intron 9 (2 samples). Somatic TP53 mutations/indels were found in six samples and high copy number amplification of MDM2 in two samples. The rearrangements caused the loss of critical parts of the protein, probably resulting in loss of function. Certain translocations in the TP53 region involved other genes (WDR25, SOX5, PNKP, ZNF787, EIF3L, ACAN, PIGU), but RNA was not available, so fusion transcripts could not be investigated. We identified one sample with a $10 \mathrm{bp}$ deletion removing the junction of exon 5 and the following intron that would affect splicing and lead to a change in the reading frame. Furthermore, 5 samples had severe somatic missense mutations in TP53, which are recorded in the COSMIC database. Three of the mutations (p.C238F, p.D281E, p.R273L) cause a loss of function of p53 [30]. Less is known about the impact of the remaining two mutations (p.I255T, p.C275Y). For all tumor samples in this study with aberrant TP53, the wild-type TP53 allele frequencies varied between $15 \%$ and $80 \%$ with a median of $30 \%$, which probably mostly originated from non-aberrant cells in the tumor stroma. In addition, 2 of the 9 samples without TP53 aberrations contained high copy number amplification of $M D M 2$ (DNA Copy Number of 20 and 60). Altogether, 18 of the 25 tumor samples harbored somatic aberrations that affect the p53 pathway. Two of the patients without detectable somatic aberrations of TP53 turned out to have germline aberrations (not shown), thus leaving only 5 of 25 without aberrations of TP53.

\section{Rearrangements of $R B 1$}

Further evaluation of findings made in cell lines revealed that $R B 1$ was recurrently affected by rearrangements in 3 out of 11 cell lines and in 5 out of the 25 tumor samples. Similar to TP53, rearrangements varied and did not generate a specific recurrent gene fusion but rather a truncation or deletion of the transcripts.

The cell lines IOR/OS10 and IOR/SARG exhibited almost undetectable expression of $R B 1$. The SNP$\mathrm{CGH}$ data from a previous study [3] of these cell lines confirmed a heterozygous deletion in IOR/OS10 in the $R B 1$ region and a copy number increase at the beginning of the gene, creating a breakpoint in IOR/SARG. In Saos-2 the transcript was truncated after exon 20, with evidence of a $7.5 \mathrm{Mb}$ deletion in the RNA-Seq data. In the tumor cohort we identified 5 samples harboring rearrangements in or around the $R B 1$ locus, with 4 samples containing translocations ( 2 in intron 2, 1 in intron 7,1 in intron 21 ) and one sample with a $2.7 \mathrm{Mb}$ deletion covering the whole gene. All patient samples with $R B 1$ aberrations also showed TP53 aberrations.

\section{$M T A P$ rearrangements with $C D K N 2 A$ co-deletions}

An $M T A P-B C N 2$ fusion transcript was identified in the osteosarcoma cell line MG-63 by RNA-Seq and confirmed as a genomic inversion on chromosome 9 . The specific fusion transcript was not recurrent, but further investigation revealed two more cell lines containing $M T A P$ rearrangements. The cell lines IOR/OS15 and IOR/OS18 showed no detectable expression, which was caused by a genomic $2.95 \mathrm{Mb}$ deletion in IOR/OS18 and unbalanced translocation $35 \mathrm{~kb}$ upstream in IOR/OS15. In all three cases, the neighboring $C D K N 2 A$ locus was codeleted. In addition, in the patient cohort, we identified rearrangements of MTAP in three of the 25 samples. One sample contained three different unbalanced translocations in the MTAP region, whereas the other two contained different deletions, including a complete deletion of the gene and a deletion in intron 4 leading to a truncation from exon 5 and upstream. As in the cell lines, the CDKN2A locus was co-affected in all three cases. Further two of the patient samples with $M T A P / C D K N 2 A$ aberrations did not show any TP53, RB1 or $M D M 2$ aberration.

\section{DISCUSSION}

Combining extensive information about structural genomic aberrations and their consequences at the RNA 
level revealed highly frequent rearrangements affecting the tumor suppressor genes TP53, RB1 and CDKN2A, and for the first time a recurrent gene fusion, involving $P M P 22$ and ELOVL5, and extensive transcript fusion without genomic evidence as a characteristic of osteosarcoma.

At RNA level the validation rate of $76 \%$ of the 17 candidate fusion transcripts tested here suggests a high likelihood for the remaining candidates to be valid, although the majority of fusion transcripts could not be confirmed at the genome level. Even for six of the extensively validated RNA fusions we could not find any evidence of an underlying genomic rearrangement. Although it is possible that this in certain cases was caused by the moderate coverage of WGS combined with aneuploidy, it seems unlikely that this would explain the discrepancy in all cases. Thus, biological mechanisms, such as trans-splicing or errors of the transcription processes, are more likely to explain those fusion transcripts. Such chimeric transcripts are found in normal human cells including stem cells and are shown to play important roles, i.e. in human embryonic stem cell pluripotency $[31,32]$. In prostate cancer [33] and colorectal cancer [34] a high number of fusion transcripts were identified also with subsets detected in benign tissue. Further, in a subset of prostate cancer a highly induced, androgen-regulated fusion transcript (SLC45A3-ELK4) was identified, mainly occurring through a mechanism other than genomic rearrangements [35]. These studies also showed that genes involved in fusion transcripts were highly tissue specific and significantly enriched for high expression, whereas the fusion transcripts themselves were modestly expressed, as was also observed for most of the fusion transcripts in our study. Further, we confirmed the expression of EIF5A-HMGN2 and EEF1A1-VIM fusion transcripts with exactly the same chimeric structure in normal bone and primary osteoblasts, suggesting a normal precise mechanism independent of gene rearrangements. As we could not detect expression of these transcripts in other tissues, they appear to be bone-specific. In general, our results suggest that the majority of fusion transcripts in osteosarcoma are generated at the RNA level, and further studies are necessary to determine the mechanisms involved and their biological impact in both normal cells and cancer. The hyperactive production of fusion transcripts thus appears to be a phenotype of osteosarcoma and recurrent fusion transcripts represent putative biomarkers.

WGS confirmed the complexity and high level of heterogeneity of osteosarcoma genomes. We found strong evidence for the involvement of non-homologous endjoining (NHEJ) and microhomology-mediated end-joining (MMEJ) DNA repair in the generation of the structural aberrations of the genome. Our results further indicate that MMEJ was primarily involved in the generation of deletions shorter than $5 \mathrm{~kb}$. This result is consistent with earlier studies showing that MMEJ repair of double-strand breaks (DSB) most often results in deletions [36].

The clustering of genome rearrangements observed was similar to what has been described for chromothripsis [20]. However, in contrast to classical chromothripsis, a Localization of genomic aberrations of TP53

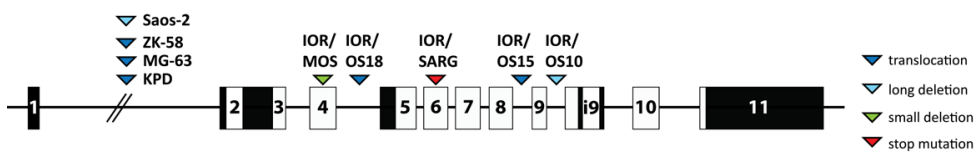

C Causes of $\mathrm{p} 53$ inactivation

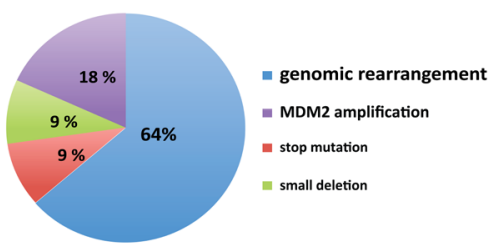

b Resulting $\mathrm{p} 53$ protein aberrations

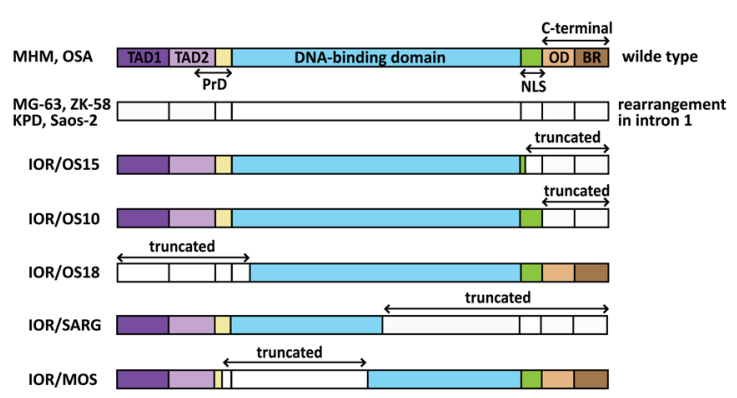

d Consequences on p53 down stream target activity

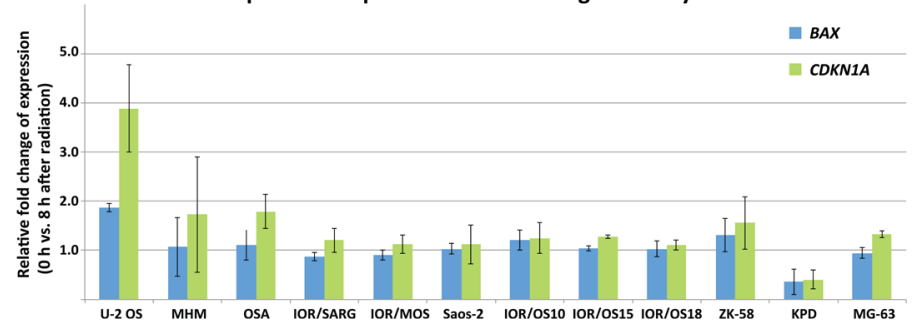

Figure 4: TP53 aberrations in osteosarcoma cell lines. a. Genomic localization of aberrations across TP53 with triangles demonstrating the position of the aberrations for the different cell lines and the aberration type (dark blue $=$ translocation, light blue $=$ long deletion, green $=$ small deletion, red $=$ stop mutation). $\mathbf{b}$. Visualization of the consequences of the TP53 aberrations at the protein level. The different protein domains are indicated (TAD = transactivation domain, NLS = nuclear localization signal, OD = oligomerization domain, $\mathrm{BR}=$ basic region). Uncolored regions of the protein represent truncated parts. $\mathbf{c}$. The distribution of the various causes of $\mathrm{p} 53$ inactivation clearly shows that rearrangements in TP53 are the major factor with $64 \%$ followed by MDM2 amplifications, small deletions and mutations. d. Results of the radiation-induced DNA damage assay showing the fold change of $B A X$ and $C D K N 1 A$ expression 8 hours after induction. U-2 OS is known to harbor wild-type p53 and was used as control. 
the associated DNA copy number increase suggests the involvement of microhomology mediated breakinduced replication (MMBIR). This process can generate chromothripsis-like complex genomic rearrangements that include amplification through increased replication at DSBs [37]. As this mechanism and the increased level of MMEJ can explain the majority of rearrangements, and both are connected to replication forks collapsed in the S-phase, this process is likely to be a major factor in osteosarcoma. Further investigation of the cell cycle and replication mechanisms could provide additional information on how MMBIR and MMEJ are activated in osteosarcoma and whether the observed absence of p53-induced DNA damage response is required for such activation. Overexpression of exogenous wild-type p53 or its reactivation in osteosarcoma cell lines with amplification of MDM2 causes cell cycle arrest, indicating that the conditions for growth arrest are present, but the $\mathrm{p} 53$ response is lacking $[27,28]$. This defect most likely leads to a further increase of DSBs and the need for MMBIR and MMEJ to repair them, leading again to an increased number of rearrangements. This scenario would also explain the high degree of heterogeneity in osteosarcomas, as these continuous processes would generate new rearrangements at each cell division.

In total, 19 fusion transcripts caused by genomic rearrangements were identified in three of the four cell lines analyzed by WGS and only one, PMP22ELOVL5, could be further validated in multiple samples. The recurrent PMP22-ELOVL5 fusion transcript was detected in four cell lines, one xenograft and two patient samples. This specific fusion was not observed in any of the 25 tumors analyzed by WGS, but one contained a translocation of PMP22 but fused to an intergenic region. Due to the lack of RNA from the patient samples, the presence of a fusion transcript could not be investigated. Observed in 7 independent samples, this is the first recurrent translocation to be identified in osteosarcoma. The PMP22 gene encodes a $22 \mathrm{kDa}$ glycoprotein member of an extended family of tetraspan membrane proteins that play important roles in myelin membrane formation and, when mutated, are responsible for a set of inherited peripheral neuropathies, including Charcot-MarieTooth disease [38]. Further studies have demonstrated that PMP22 can regulate cell death, shape, migration, and its involvement in the p53-dependent apoptotic response in several cell types [39, 40]. Inhibition of the p53-dependent apoptotic response by growth arrest attenuated $P M P 22$ expression, whereas overexpression of $P M P 22$ could trigger an apoptotic response. Thus, the general inactivation of p53 described here could explain the reported lack of induction of PMP22 expression in growth-arrested osteosarcoma cell lines, including MG63 [41]. Mutations within the transmembrane domains of PMP22 cause impaired transport to the cell surface and intracellular accumulation [42]. These mutants were also unable to induce cell death. The resulting PMP22ELOVL5 fusion protein has lost the last 54 amino acids of PMP22, which code for parts of the third and the complete fourth transmembrane domain, possibly resulting in loss of tumor suppressor activity. However, the relationships of PMP22 expression level to prognosis and the outcome of different cancer types are contradictory [43-45].

ELOVL5 is a fatty acid elongase located in the plasma membrane. Very little is known about its possible association with cancer, apart from a study reporting down-regulation of ELOVL5 in prostate cancer tissue [46]. However, this was not the case in our osteosarcoma cell lines.

The most striking finding in our study was the high frequency of rearrangements affecting TP53. Inactivating genomic rearrangements were identified in 7 of 11 cell lines and 10 of 25 patient biopsies. TP53 intragenic rearrangements represent a new mechanism of p53 inactivation and are very frequent in osteosarcoma [17, 19]. Two cell lines (IOR/MOS, IOR/SARG) and 5 tumors were affected by previously described point mutations that caused partial loss of function of p53 [30]. Two cell lines (MHM, OSA) and two tumor samples harboring wild type p53 showed inactivation of the p53 pathway by MDM2 gene amplification [47]. Our radiation-induced DNA damage assay verified that p53 activity is compromised in all examined cell lines except for U-2 OS, which was used as a wild-type TP53 control. Although this result may not be surprising for a tumor type with such chaotic genomes, we cannot exclude that this strikingly high prevalence in cell lines is selected for during in vitro culture. The analysis of 25 full-genome sequences from patient biopsies revealed a similar pattern of TP53 rearrangement in $40 \%$ of the samples. Altogether, our results show that p53 inactivation in osteosarcomas by rearrangement (40 $\%)$, mutation/indels (24\%) or MDM2 amplification (8 $\%$ ) is much more frequent than previously reported [12, 48]. Additionally two samples showed germ line TP53 aberrations (not shown). This confirms the key role of p53 in osteosarcoma, consistent with its critical role in Li-Fraumeni syndrome and osteoblast biology [49]. The frequent structural rearrangements of TP53 with a hotspot in intron 1 ( 5 patient samples, 4 cell lines) were also found in two recent WGS studies of osteosarcomas [17, 18]. In addition, intron 9 was also found to be frequently affected by rearrangements ( 2 patient samples, 1 cell line) representing a second hotspot. In contrast to the previous study, 5 of our osteosarcoma patient samples (20\%) did not show any aberration of TP53, RB1 or MDM2. But two of these samples showed $M T A P$ rearrangement with $C D K N 2 A$ co-deletion. $C D K N 2 A$ codes for an inhibitor of CDK4, already known to be critical in the regulation of the activity of retinoblastoma protein (RB1) [50], and also encodes $\mathrm{p} 14^{\mathrm{ARF}}$, which targets MDM2 for degradation [51], probably causing an inhibition of the p53 and RB1 pathways in these two cases. 
MTAP encodes methylthioadenosine phosphorylase, essential for adenine and methionine synthesis, and was deleted in $38 \%$ of osteosarcoma tumors [52]. Mutations in MTAP may result in diaphyseal medullary stenosis with malignant fibrous histiocytoma (DMS-MFH), an autosomal-dominant syndrome characterized by bone dysplasia, myopathy, and bone cancer [53]. As found in our study, the tumor suppressor gene $C D K N 2 A$ was always co-affected, and it is likely that $C D K N 2 A$ is the main target.

Further, the $R B 1$ locus was frequently affected (20\%), RB1 being essential for the regulation of cell cycle progression at the $\mathrm{G} 1 / \mathrm{S}$ checkpoint. In previous studies, $25-35 \%$ of osteosarcomas showed mutations or rearrangements of $R B 1[17,54]$.

The molecular dissection of osteosarcoma revealed an extraordinary degree of genome rearrangement harboring highly recurrent cancer specific aberrations, the involvement of microhomology mediated repair mechanism and extensive transcript fusions, apparently caused by a trans-splicing phenotype. Furthermore, we identified systematic inactivation of the p53 pathway by rearrangements of TP53. Unscrambling the genomic chaos of osteosarcoma at base-pair resolution provided new insights in mechanisms involved in osteosarcoma development and may contribute to develop new diagnostic and therapeutic strategies.

\section{MATERIALS AND METHODS}

\section{Samples}

Tumor samples were collected at the Department of Pathology, Oslo University Hospital, and diagnosed according to the current World Health Organization classification [55]. The project and informed consent were approved by the Ethical committee of Southern Norway (Project S-06133). Data for all tumor samples are summarized in Supplementary Table S1. Nineteen osteosarcoma cell lines from the EuroBoNeT panel [26] plus G-292 (ATCC, Manassas, VA, USA) and Cal72 (University College London, London, UK) were also analyzed, 11 of which were included in the NGS analysis. All cell lines were mycoplasma negative and authenticated by STR DNA profiling using Powerplex 16 (Promega, Madison, WI, USA); the data were validated using the known profiles of the EuroBoNeT cell bank and ATCC.

Normal bone samples were obtained from amputations of osteosarcoma cancer patients, collected as far away as possible from the tumor site and exhibiting normal DNA copy numbers. Two other normal bone samples were purchased from Capital Biosciences (Gaithersburg, MD, USA). Two normal osteoblast samples were from human calvaria (ScienCell Research
Laboratories, San Diego, CA, USA), and two were from femur and tibia (Cambrex BioScience, Maryland, USA). Data for all normal samples are given in Supplementary Table S4. For RNA-Seq analysis, a mesenchymal stromal cell (MSC) line, undifferentiated and differentiated into osteoblasts, was used as a normal control [24].

The sample set of the 25 osteosarcoma tumor samples is a part of the Bone cancer project of the International Cancer Genome Consortium (IGCG) and sequencing data were generated at the Wellcome Trust Sanger Institute (Hinxton, UK).

\section{Library preparation and sequencing}

Genomic DNA isolation was conducted using Wizard Genomic DNA Purification Kit (Promega), and total RNA was isolated using the miRNeasy Mini Kit from QIAGEN (Germany). Total RNA was assessed for quality on an Agilent Technologies 2100 Bioanalyzer (Agilent Technologies Inc., CA, USA).

RNA sequencing libraries were created using the Illumina TruSeq RNA Sample Preparation Kit v2 (Illumina Inc., CA, USA), and $1 \mu \mathrm{g}$ high-quality total RNA starting material was processed according to the manufacturer's instructions.

The resulting libraries were sequenced on the Genome Analyzer IIx using TruSeq SBS Kit v5 to perform paired-end runs with $75 \mathrm{bp}$ sequence length $(2 \times 75 \mathrm{bp})$. Real-time analysis and base calling were conducted by Illumina's software packages SCS2.8/RTA1.8 and Off-line Basecaller v1.8.

DNA library construction and whole genome sequencing (WGS) of four cell lines were conducted at the Beijing Genomics Institute (www.genomics.cn) using paired-end sequencing, 2x 100 bp read length and $500 \mathrm{bp}$ fragment length on the Illumina HiSeq platform.

The sequencing data generated in this project were submitted to the European Nucleotide Archive (ENA) and are available under accession number PRJEB7574.

\section{RNA-Seq data analysis}

RNA-Seq data were analyzed using the deFuse algorithm [56] and TRUP [57], both of which are computational methods for fusion RNA discovery. Applying these methods, paired-end reads were aligned to the Homo sapiens GRC37.58 assembly to detect fusion events by resolving ambiguous discordant alignments and identifying the most likely assignment of reads spanning a breakpoint (spanning reads) and reads harboring a breakpoint (breakpoint-covering reads). Both methods additionally combine the read-pair analysis with de novo assembly. The predominantly overlapping results from both tools were combined for further analysis.

Possible mapping artifacts, ribosomal 
contamination, and normal trans-splicing events were removed by filtering out any potential candidate fusions detected in the 16 normal tissues available from Illumina's BodyMap2.0 (Gary Schroth, Illumina), as well as candidates with very high repetition or low complexity sequence $200 \mathrm{bp}$ around the breakpoint. Finally, only fusion transcripts with at least 8 breakpoint-spanning and 3 breakpoint-covering (split) reads were reported.

Transcript expression analysis was conducted using the TopHat/Cufflinks/Cuffcompare pipeline [58], and differences in expression values were determined by the Wilcoxon rank-sum test, assuming the observations from the different groups to be independent of each other and equal under the null hypothesis.

\section{DNA-Seq data analysis}

The DNA sequencing data were mapped to the human genome build hg19 (http://hgdownload.cse.ucsc. edu/goldenPath/hg19/bigZips/) using BWA (v0.6.1) and genomic structural variants at single base pair resolution by integrated paired-end and split-read analysis by DELLY [59], requiring at least 8 spanning reads and 3 breakpointcovering reads. Overlapping homologies at the breakpoint junctions, also identified using DELLY, were divided into three groups: no overlap, 1-5 bp and 6-25 bp long microhomology. To test for randomness, the distributions among the groups for all types of rearrangements were compared to the distributions of microhomologies identified by analyzing 500 random sequences that represent the average genome (described by Vissers et al.) [60], using Fisher's exact test for count data with simulated p-values (based on $1.00 \mathrm{e}+05$ replicates).

The allele frequency of interchromosomal translocations was calculated by comparing the number of concordant reads and number of breakpoints spanning and covering reads in a 500-bp window around the breakpoint. Further statistical analysis on the clustering of breakpoints and the randomness of aberration types (deletion, insertion, tandem duplication, translocation) was conducted in the statistical programming language $\mathrm{R}$ following the recommendations of Korbel and Campbell in "Criteria for Inference of Chromothripsis in Cancer Genomes" [20].

\section{Validation and screening}

Primers for breakpoint-spanning PCR were placed approximately $100 \mathrm{bp}$ upstream and downstream from the breakpoint and designed by the NCBI primer-designing tool (http://www.ncbi.nlm.nih.gov/tools/primer-blast/). If agarose gel electrophoresis showed a PCR product in the expected size range, the band was isolated and analyzed by Sanger sequencing at Eurofins MWG (Eurofins Genomics, Ebersberg, Germany). Detection of expression was conducted using TaqMan Gene expression assays (Life Technologies, CA, USA), manually designed using PrimerExpress v3 with probes located over the breakpoint of the fusion transcript to be able to distinguish the normal transcripts and specifically measure expression of the fusions. The 5'- and 3'- ends of individual fusion transcripts were amplified using a SMARTer 5' - and 3'RACE PCR kit (Clontech Laboratories, Inc., CA, USA).

\section{Cytogenetic techniques}

FISH (Fluorescence in situ hybridization) was used to validate the underlying genomic rearrangements using formalin-fixed paraffin-embedded tissue array slides (tissue microarrays, TMAs) of 20 osteosarcoma cell lines and BACs covering PMP22 (RP11-47J1) and ELOVL5 (RP11-142f5). To generate TMAs, each cell line was cultured in $6-875 \mathrm{~cm}^{2}$ cell culture flasks. Cells were washed with RPMI and scraped out with $1 \mathrm{ml} 4 \%$ formalin and sedimented by brief centrifugation. The cell pellets were treated for at least 48 hours in formalin. Before pellets were embedded in paraffin, the cells were dehydrated in ethanol (70, 90, 95, and 99\%) and xylene. To produce a cell line array of all of the cell lines, punches of $2 \mathrm{~mm}$ in diameter of the embedded cells were arranged on one prepared paraffin block (Beecher Instruments, WI). Interphase FISH and spectral karyotyping (SKY) were performed according to previously described protocols by Kresse et al. (2012) [3].

\section{Radiation-induced DNA damage}

The cell lines were plated in 6-well plates at $80 \%$ confluence and left to attach overnight. The following day, the cells were irradiated with 5 Gy using an X-ray generator (Faxitron CP160, 160kV, $6.3 \mathrm{~mA}$ ). The cells were harvested at $0 \mathrm{~h}$ and $8 \mathrm{~h}$ after irradiation using a cell scraper and ice-cold PBS solution (Lonza). The cells were spun down at $300 \times g$ for $5 \mathrm{~min}$ and immediately frozen at $-80{ }^{\circ} \mathrm{C}$. RNA was isolated from the pellets using the RNeasy micro kit (QIAGEN) and reverse-transcribed to cDNA using the SuperScript VILO cDNA synthesis kit (Life Technologies) according to the manufacturer's instructions. For gene expression analysis of CDKN1A (assay ID: Hs00355782_m1) and $B A X$ (assay ID: Hs00355782_m1), quantitative real-time RT-PCR (qRTPCR) was performed using TaqMan Gene Expression Assays (Life Technologies). Relative expression was analyzed using the $2^{-\Delta \Delta \mathrm{Ct}}$-method [61], using TATA-box binding protein (TBP, assay ID Hs99999910_m1) as an endogenous reference for normalization.

\section{ACKNOWLEDGMENTS}

The cell line tissue array was produced by the 
EuroBoNeT Network of Excellence on Bone Tumors. The authors especially thank the International Cancer Genome Consortium, Bone cancer project for making the Norwegian osteosarcoma tumor data available. Further we thank Dr. Gary Schroth from Illumina for giving access to the data of the Illumina Body Map 2.0, Dr. Massimo Serra (Istituto Ortopedico Rizzoli, Italy) for providing the IOR osteosarcoma cell lines, Prof. Antonio LlombartBosch (Medical School of Valencia University, Spain) for providing the xenografts and the Genomics Core Facility at the Norwegian Radium Hospital (Oslo, Norway) for technical support.

\section{FUNDING}

This work was supported by the Research Council of Norway [grant numbers 218241 and 193056]; the Norwegian Cancer Society [grant numbers PR-2007-0163 and 71572 - PR-2006-0396]; the University of Oslo and the charities Defense Against Cancer and Support Group for Children with Cancer.

\section{CONFLICTS OF INTEREST}

The authors disclose no potential conflicts of interest.

\section{REFERENCES}

1. Bayani J, Zielenska M, Pandita A, Al-Romaih K, Karaskova J, Harrison K, Bridge JA, Sorensen P, Thorner $\mathrm{P}$ and Squire JA. Spectral karyotyping identifies recurrent complex rearrangements of chromosomes 8,17 , and 20 in osteosarcomas. Genes Chromosomes Cancer. 2003; 36:716.

2. Kuijjer ML, Rydbeck H, Kresse SH, Buddingh EP, Lid AB, Roelofs H, Burger H, Myklebost O, Hogendoorn PC, Meza-Zepeda LA and Cleton-Jansen AM. Identification of osteosarcoma driver genes by integrative analysis of copy number and gene expression data. Genes Chromosomes Cancer. 2012; 51:696-706.

3. Kresse SH, Rydbeck H, Skarn M, Namlos HM, BarraganPolania AH, Cleton-Jansen AM, Serra M, Liestol K, Hogendoorn PC, Hovig E, Myklebost O and Meza-Zepeda LA. Integrative analysis reveals relationships of genetic and epigenetic alterations in osteosarcoma. PLoS One. 2012; 7:e48262.

4. Kresse SH, Ohnstad HO, Paulsen EB, Bjerkehagen B, Szuhai K, Serra M, Schaefer KL, Myklebost O and MezaZepeda LA. LSAMP, a novel candidate tumor suppressor gene in human osteosarcomas, identified by array comparative genomic hybridization. Genes Chromosomes Cancer. 2009; 48:679-693.

5. Baroy T, Kresse SH, Skarn M, Stabell M, Castro R, Lauvrak S, Llombart-Bosch A, Myklebost $\mathrm{O}$ and Meza-Zepeda
LA. Reexpression of LSAMP inhibits tumor growth in a preclinical osteosarcoma model. Mol Cancer. 2014; 13:93.

6. Berner JM, Forus A, Elkahloun A, Meltzer PS, Fodstad $\mathrm{O}$ and Myklebost $\mathrm{O}$. Separate amplified regions encompassing CDK4 and MDM2 in human sarcomas. Genes Chromosomes Cancer. 1996; 17:254-259.

7. Ewen ME, Sluss HK, Sherr CJ, Matsushime H, Kato $\mathrm{J}$ and Livingston DM. Functional interactions of the retinoblastoma protein with mammalian D-type cyclins. Cell. 1993; 73:487-497.

8. Momand J, Zambetti GP, Olson DC, George D and Levine AJ. The mdm-2 oncogene product forms a complex with the p53 protein and inhibits p53-mediated transactivation. Cell. 1992; 69:1237-1245.

9. Draper GJ, Sanders BM and Kingston JE. Second primary neoplasms in patients with retinoblastoma. Br J Cancer. 1986; 53:661-671.

10. Malkin D, Li FP, Strong LC, Fraumeni JF, Jr., Nelson CE, Kim DH, Kassel J, Gryka MA, Bischoff FZ, Tainsky MA and et al. Germ line p53 mutations in a familial syndrome of breast cancer, sarcomas, and other neoplasms. Science. 1990; 250:1233-1238.

11. Andreassen A, Oyjord T, Hovig E, Holm R, Florenes VA, Nesland JM, Myklebost O, Hoie J, Bruland OS, Borresen $\mathrm{AL}$ and et al. p53 abnormalities in different subtypes of human sarcomas. Cancer Res. 1993; 53:468-471.

12. Wunder JS, Gokgoz N, Parkes R, Bull SB, Eskandarian S, Davis AM, Beauchamp CP, Conrad EU, Grimer RJ, Healey JH, Malkin D, Mangham DC, et al. TP53 mutations and outcome in osteosarcoma: a prospective, multicenter study. J Clin Oncol. 2005; 23:1483-1490.

13. Florenes VA, Maelandsmo GM, Forus A, Andreassen A, Myklebost $\mathrm{O}$ and Fodstad O. MDM2 gene amplification and transcript levels in human sarcomas: relationship to TP53 gene status. J Natl Cancer Inst. 1994; 86:1297-1302.

14. Kawaguchi K, Oda Y, Sakamoto A, Saito T, Tamiya S, Iwamoto $\mathrm{Y}$ and Tsuneyoshi M. Molecular analysis of p53, MDM2, and H-ras genes in osteosarcoma and malignant fibrous histiocytoma of bone in patients older than 40 years. Mod Pathol. 2002; 15:878-888.

15. Lonardo F, Ueda T, Huvos AG, Healey J and Ladanyi M. p53 and MDM2 alterations in osteosarcomas: correlation with clinicopathologic features and proliferative rate. Cancer. 1997; 79:1541-1547.

16. Henriksen J, Aagesen TH, Maelandsmo GM, Lothe $\mathrm{RA}$, Myklebost $\mathrm{O}$ and Forus A. Amplification and overexpression of COPS3 in osteosarcomas potentially target TP53 for proteasome-mediated degradation. Oncogene. 2003; 22:5358-5361.

17. Chen X, Bahrami A, Pappo A, Easton J, Dalton J, Hedlund E, Ellison D, Shurtleff S, Wu G, Wei L, Parker M, Rusch M, Nagahawatte P, Wu J, Mao S, Boggs K, et al. Recurrent somatic structural variations contribute to tumorigenesis in pediatric osteosarcoma. Cell Rep. 2014; 7:104-112. 
18. Ribi S, Baumhoer D, Lee K, Edison, Teo AS, Madan B, Zhang K, Kohlmann WK, Yao F, Lee WH, Hoi Q, Cai S, Woo XY, Tan P, Jundt G, Smida J, et al. TP53 intron 1 hotspot rearrangements are specific to sporadic osteosarcoma and can cause Li-Fraumeni syndrome. Oncotarget. 2015; 6:7727-7740. DOI: 10.18632/ oncotarget. 3115.

19. Perry JA, Kiezun A, Tonzi P, Van Allen EM, Carter SL, Baca SC, Cowley GS, Bhatt AS, Rheinbay E, Pedamallu CS, Helman E, Taylor-Weiner A, McKenna A, DeLuca DS, Lawrence MS, Ambrogio L, et al. Complementary genomic approaches highlight the PI3K/mTOR pathway as a common vulnerability in osteosarcoma. Proc Natl Acad Sci U S A. 2014; 111:E5564-5573.

20. Korbel JO and Campbell PJ. Criteria for inference of chromothripsis in cancer genomes. Cell. 2013; 152:12261236.

21. Stephens PJ, Greenman CD, Fu B, Yang F, Bignell GR, Mudie LJ, Pleasance ED, Lau KW, Beare D, Stebbings LA, McLaren S, Lin ML, McBride DJ, Varela I, Nik-Zainal S, Leroy $\mathrm{C}$, et al. Massive genomic rearrangement acquired in a single catastrophic event during cancer development. Cell. 2011; 144:27-40.

22. Kloosterman WP, Hoogstraat M, Paling O, TavakoliYaraki M, Renkens I, Vermaat JS, van Roosmalen MJ, van Lieshout S, Nijman IJ, Roessingh W, van 't Slot R, van de Belt J, Guryev V, et al. Chromothripsis is a common mechanism driving genomic rearrangements in primary and metastatic colorectal cancer. Genome Biol. 2011; 12:R103.

23. Mohseny AB, Szuhai K, Romeo S, Buddingh EP, Briairede Bruijn I, de Jong D, van Pel M, Cleton-Jansen AM and Hogendoorn PC. Osteosarcoma originates from mesenchymal stem cells in consequence of aneuploidization and genomic loss of Cdkn2. J Pathol. 2009; 219:294-305.

24. Hakelien AM, Bryne JC, Harstad KG, Lorenz S, Paulsen J, Sun J, Mikkelsen TS, Myklebost O and Meza-Zepeda LA. The regulatory landscape of osteogenic differentiation. Stem Cells. 2014; 32:2780-2793.

25. Skarn M, Noordhuis P, Wang MY, Veuger M, Kresse SH, Egeland EV, Micci F, Namlos HM, Hakelien AM, Olafsrud SM, Lorenz S, Haraldsen G, et al. Generation and characterization of an immortalized human mesenchymal stromal cell line. Stem Cells Dev. 2014; 23:2377-2389.

26. Ottaviano L, Schaefer KL, Gajewski M, Huckenbeck W, Baldus S, Rogel U, Mackintosh C, de Alava E, Myklebost O, Kresse SH, Meza-Zepeda LA, Serra M, Cleton-Jansen AM, Hogendoorn PC, Buerger H, Aigner T, et al. Molecular characterization of commonly used cell lines for bone tumor research: a trans-European EuroBoNet effort. Genes Chromosomes Cancer. 2010; 49:40-51.

27. Tovar C, Rosinski J, Filipovic Z, Higgins B, Kolinsky K, Hilton H, Zhao X, Vu BT, Qing W, Packman K, Myklebost O, Heimbrook DC and Vassilev LT. Small-molecule MDM2 antagonists reveal aberrant p53 signaling in cancer: implications for therapy. Proc Natl Acad Sci U S A. 2006;
103:1888-1893.

28. Diller L, Kassel J, Nelson CE, Gryka MA, Litwak G, Gebhardt M, Bressac B, Ozturk M, Baker SJ, Vogelstein $\mathrm{B}$ and et al. p53 functions as a cell cycle control protein in osteosarcomas. Mol Cell Biol. 1990; 10:5772-5781.

29. Zhang Y, Xiong Y and Yarbrough WG. ARF promotes MDM2 degradation and stabilizes p53: ARF-INK4a locus deletion impairs both the $\mathrm{Rb}$ and $\mathrm{p} 53$ tumor suppression pathways. Cell. 1998; 92:725-734.

30. Jordan JJ, Inga A, Conway K, Edmiston S, Carey LA, Wu L and Resnick MA. Altered-function p53 missense mutations identified in breast cancers can have subtle effects on transactivation. Mol Cancer Res. 2010; 8:701-716.

31. Frenkel-Morgenstern M, Lacroix V, Ezkurdia I, Levin Y, Gabashvili A, Prilusky J, Del Pozo A, Tress M, Johnson R, Guigo R and Valencia A. Chimeras taking shape: potential functions of proteins encoded by chimeric RNA transcripts. Genome Res. 2012; 22:1231-1242.

32. Wu CS, Yu CY, Chuang CY, Hsiao M, Kao CF, Kuo $\mathrm{HC}$ and Chuang $\mathrm{TJ}$. Integrative transcriptome sequencing identifies trans-splicing events with important roles in human embryonic stem cell pluripotency. Genome Res. $2014 ; 24: 25-36$.

33. Kannan K, Wang L, Wang J, Ittmann MM, Li W and Yen L. Recurrent chimeric RNAs enriched in human prostate cancer identified by deep sequencing. Proc Natl Acad Sci U S A. 2011; 108:9172-9177.

34. Nome T, Thomassen GO, Bruun J, Ahlquist T, Bakken AC, Hoff AM, Rognum T, Nesbakken A, Lorenz S, Sun J, Barros-Silva JD, Lind GE, Myklebost O, Teixeira MR, Meza-Zepeda LA, Lothe RA, et al. Common fusion transcripts identified in colorectal cancer cell lines by highthroughput RNA sequencing. Transl Oncol. 2013; 6:546553.

35. Rickman DS, Pflueger D, Moss B, VanDoren VE, Chen CX, de la Taille A, Kuefer R, Tewari AK, Setlur SR, Demichelis $\mathrm{F}$ and Rubin MA. SLC45A3-ELK4 is a novel and frequent erythroblast transformation-specific fusion transcript in prostate cancer. Cancer Res. 2009; 69:2734-2738.

36. McVey M and Lee SE. MMEJ repair of double-strand breaks (director's cut): deleted sequences and alternative endings. Trends Genet. 2008; 24:529-538.

37. Liu P, Erez A, Nagamani SC, Dhar SU, Kolodziejska KE, Dharmadhikari AV, Cooper ML, Wiszniewska J, Zhang F, Withers MA, Bacino CA, Campos-Acevedo LD, Delgado MR, Freedenberg D, Garnica A, Grebe TA, et al. Chromosome catastrophes involve replication mechanisms generating complex genomic rearrangements. Cell. 2011; 146:889-903.

38. Murakami T, Garcia CA, Reiter LT and Lupski JR. CharcotMarie-Tooth disease and related inherited neuropathies. Medicine. 1996; 75:233-250.

39. Fabbretti E, Edomi P, Brancolini C and Schneider C. Apoptotic phenotype induced by overexpression of 
wild-type gas3/PMP22: its relation to the demyelinating peripheral neuropathy CMT1A. Genes Dev. 1995; 9:18461856.

40. Brancolini C, Marzinotto S and Schneider C. Susceptibility to p53 dependent apoptosis correlates with increased levels of Gas2 and Gas3 proteins. Cell Death Differ. 1997; 4:247253.

41. van Dartel M and Hulsebos TJ. Characterization of PMP22 expression in osteosarcoma. Cancer Genet Cytogenet. 2004; 152:113-118.

42. Brancolini C, Marzinotto S, Edomi P, Agostoni E, Fiorentini C, Muller HW and Schneider C. Rho-dependent regulation of cell spreading by the tetraspan membrane protein Gas3/ PMP22. Mol Biol Cell. 1999; 10:2441-2459.

43. Mimori K, Kataoka A, Yoshinaga K, Ohta M, Sagara Y, Yoshikawa Y, Ohno S, Barnard GF and Mori M. Identification of molecular markers for metastasis-related genes in primary breast cancer cells. Clin Exp Metastasis. 2005; 22:59-67.

44. Tong D, Heinze G, Pils D, Wolf A, Singer CF, Concin N, Hofstetter G, Schiebel I, Rudas M and Zeillinger R. Gene expression of PMP22 is an independent prognostic factor for disease-free and overall survival in breast cancer patients. BMC Cancer. 2010; 10:682.

45. Irshad S, Bansal M, Castillo-Martin M, Zheng T, Aytes A, Wenske S, Le Magnen C, Guarnieri P, Sumazin P, Benson MC, Shen MM, Califano A and Abate-Shen C. A molecular signature predictive of indolent prostate cancer. Sci Transl Med. 2013; 5:202ra122.

46. Romanuik TL, Ueda T, Le N, Haile S, Yong TM, Thomson T, Vessella RL and Sadar MD. Novel biomarkers for prostate cancer including noncoding transcripts. Am J Pathol. 2009; 175:2264-2276.

47. Kubbutat MH, Jones SN and Vousden KH. Regulation of p53 stability by Mdm2. Nature. 1997; 387:299-303.

48. Overholtzer M, Rao PH, Favis R, Lu XY, Elowitz MB, Barany F, Ladanyi M, Gorlick R and Levine AJ. The presence of p53 mutations in human osteosarcomas correlates with high levels of genomic instability. Proc Natl Acad Sci U S A. 2003; 100:11547-11552.

49. Lengner CJ, Steinman HA, Gagnon J, Smith TW, Henderson JE, Kream BE, Stein GS, Lian JB and Jones SN. Osteoblast differentiation and skeletal development are regulated by Mdm2-p53 signaling. The Journal of cell biology. 2006; 172:909-921.

50. Serrano M, Hannon GJ and Beach D. A new regulatory motif in cell-cycle control causing specific inhibition of cyclin D/CDK4. Nature. 1993; 366:704-707.

51. Stott FJ, Bates S, James MC, McConnell BB, Starborg M, Brookes S, Palmero I, Ryan K, Hara E, Vousden KH and Peters G. The alternative product from the human CDKN2A locus, p14(ARF), participates in a regulatory feedback loop with p53 and MDM2. EMBO J. 1998; 17:5001-5014.

52. Garcia-Castellano JM, Villanueva A, Healey JH, Sowers
R, Cordon-Cardo C, Huvos A, Bertino JR, Meyers P and Gorlick R. Methylthioadenosine phosphorylase gene deletions are common in osteosarcoma. Clin Cancer Res. 2002; 8:782-787.

53. Camacho-Vanegas O, Camacho SC, Till J, MirandaLorenzo I, Terzo E, Ramirez MC, Schramm V, Cordovano G, Watts G, Mehta S, Kimonis V, Hoch B, Philibert KD, Raabe CA, Bishop DF, Glucksman MJ, et al. Primate genome gain and loss: a bone dysplasia, muscular dystrophy, and bone cancer syndrome resulting from mutated retroviral-derived MTAP transcripts. American journal of human genetics. 2012; 90:614-627.

54. Martin JW, Squire JA and Zielenska M. The genetics of osteosarcoma. Sarcoma. 2012; 2012:627254.

55. Fletcher CDMU, K. K.; Mertens, F. World Health Organization classification of tumors, pathology and genetics of tumors of soft tissue and bone. (Lyon, France: IARC Press). 2002.

56. McPherson A, Hormozdiari F, Zayed A, Giuliany R, Ha G, Sun MG, Griffith M, Heravi Moussavi A, Senz J, Melnyk N, Pacheco M, Marra MA, Hirst M, Nielsen TO, Sahinalp $\mathrm{SC}$, Huntsman D, et al. deFuse: an algorithm for gene fusion discovery in tumor RNA-Seq data. PLoS Comput Biol. 2011; 7:e1001138.

57. Fernandez-Cuesta L, Sun R, Menon R, George J, Lorenz S, Meza-Zepeda L, Peifer M, Plenker D, Heuckmann J, Leenders F, Zander T, Dahmen I, Koker M, Schottle $\mathrm{J}$, Ullrich R, Altmuller J, et al. Identification of novel fusion genes in lung cancer using breakpoint assembly of transcriptome sequencing data. Genome Biol. 2015; 16:7.

58. Trapnell C, Roberts A, Goff L, Pertea G, Kim D, Kelley DR, Pimentel H, Salzberg SL, Rinn JL and Pachter L. Differential gene and transcript expression analysis of RNA-seq experiments with TopHat and Cufflinks. Nat Protoc. 2012; 7:562-578.

59. Rausch T, Zichner T, Schlattl A, Stutz AM, Benes V and Korbel JO. DELLY: structural variant discovery by integrated paired-end and split-read analysis. Bioinformatics. 2012; 28:i333-i339.

60. Vissers LE, Bhatt SS, Janssen IM, Xia Z, Lalani SR, Pfundt R, Derwinska K, de Vries BB, Gilissen C, Hoischen A, Nesteruk M, Wisniowiecka-Kowalnik B, Smyk M, Brunner HG, Cheung SW, van Kessel AG, et al. Rare pathogenic microdeletions and tandem duplications are microhomology-mediated and stimulated by local genomic architecture. Hum Mol Genet. 2009; 18:3579-3593.

61. Livak KJ and Schmittgen TD. Analysis of relative gene expression data using real-time quantitative PCR and the 2(-Delta Delta C(T)) Method. Methods. 2001; 25:402-408. 